\title{
Endoscopic necrosectomy through a lumen-apposing metal stent resulting in perforation: is it time to develop dedicated accessories?
}

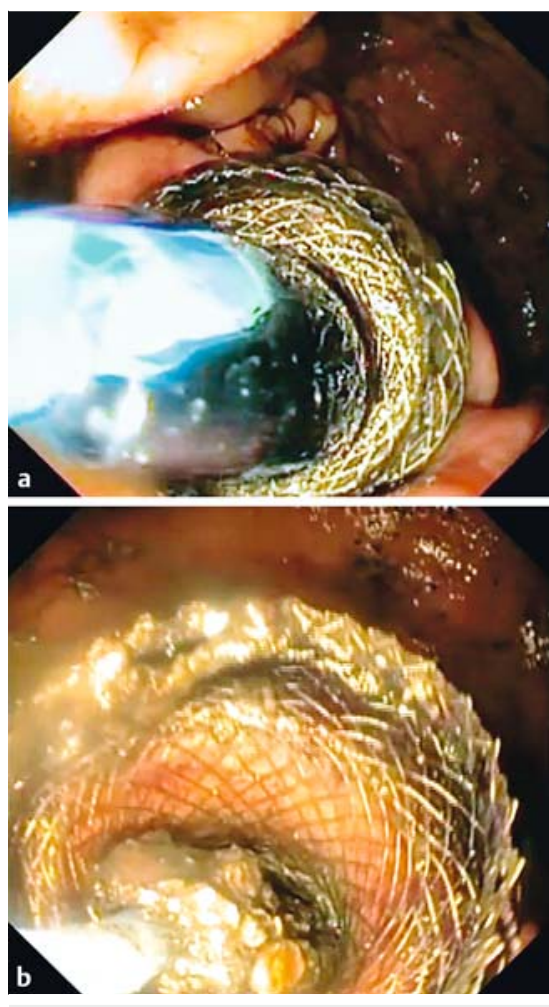

- Fig. 1 Endoscopic images showing: a balloon dilation, up to $18 \mathrm{~mm}$, of the central part of the lumen-apposing selfexpandable metal stent that had been placed between the gastric lumen and the cavity of the walled-off pancreatic necrosis (WOPN); b removal of necrotic material from the cavity of the WOPN using a Dormia basket.

A novel lumen-apposing self-expandable metal stent (LAMS; Axios EC; Boston Scientific Corp., Marlborough, Massachusetts, USA) that is able to create a stable communicating fistulous tract has simplified the performance of endoscopic necrosectomy for walled-off pancreatic necrosis (WOPN).

A 44-year-old man with a $10-\mathrm{cm}$ WOPN (>50\% solid component) underwent successful endoscopic ultrasound (EUS)guided drainage with placement of a LAMS (15-mm wide $\times 10-\mathrm{mm}$ long). Balloon dilation of the central part of

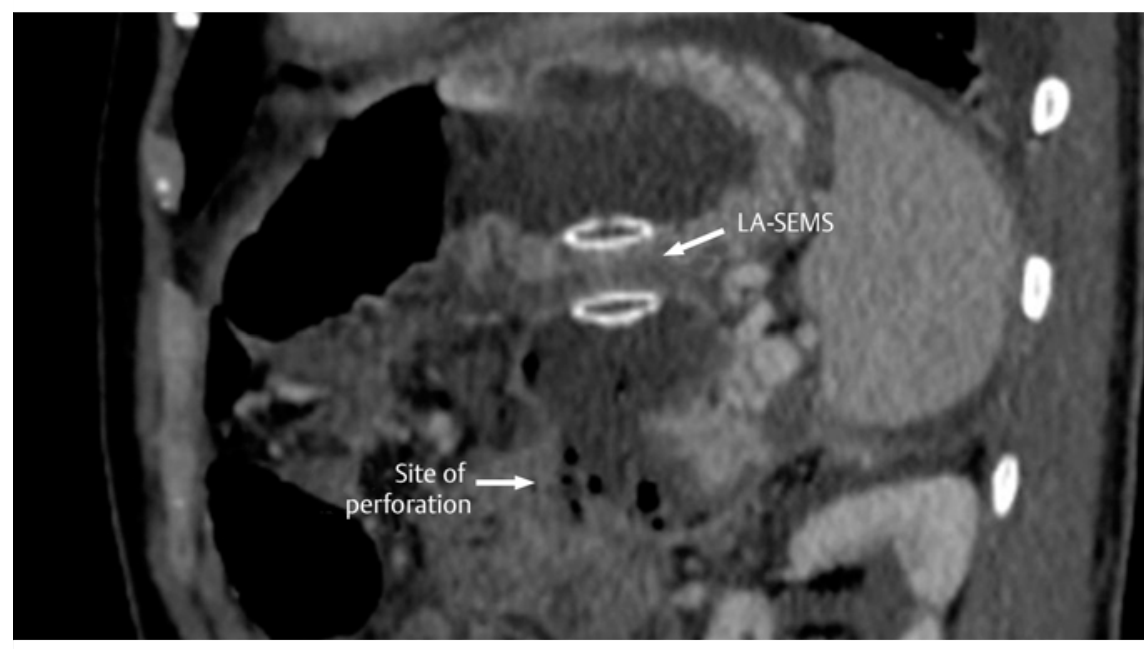

- Fig. 2 Computed tomography image showing the perforation site of the walled-off pancreatic necrosis, which was located on the opposite wall of the cavity to the lumen-apposing self-expandable metal stent (LAMS).
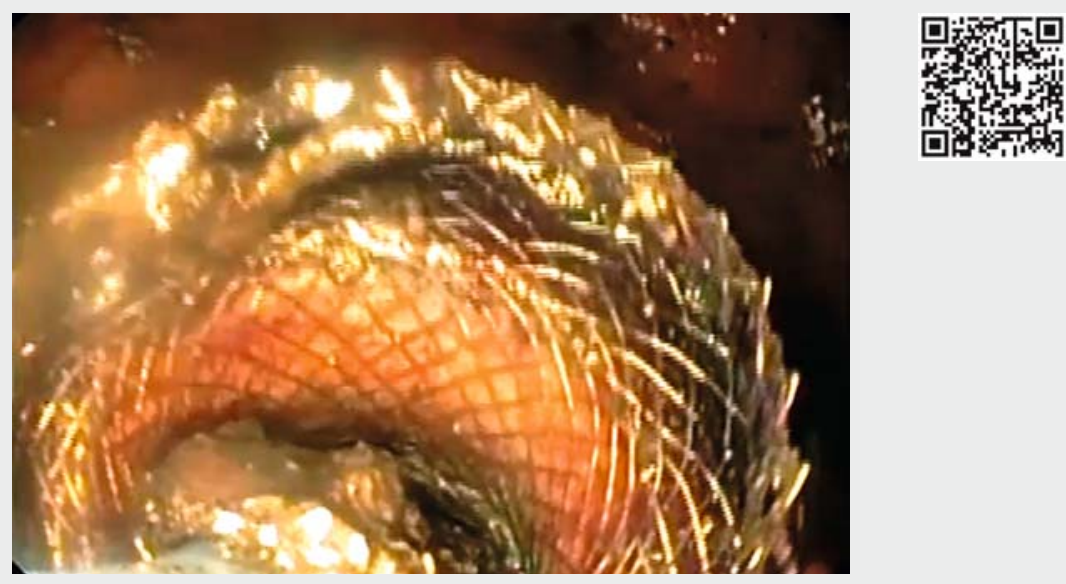

Video 1 Video showing endoscopic ultrasound drainage of a walled-off pancreatic necrosis lesion followed by necrosectomy, which resulted in perforation of the cavity on the opposite wall to the position of the lumen-apposing metal stent.

the stent up to $18 \mathrm{~mm}$ was performed ( Fig.1a), followed by removal of necrotic debris using various Dormia baskets ( $>$ Fig. 1 b; $>$ Video 1 ) and instillation of hydrogen peroxide into the cavity. The following day, the patient devel- oped peritoneal signs and an abdominal computed tomography (CT) scan showed perforation of the wall of the WOPN on the opposite side to the position of the stent ( $>$ Fig. 2). He underwent successful surgery. After the videos of the proce- 
dure had been reviewed, it was judged that the tip of the balloon dilator was most likely to have been the cause of the perforation.

Among the various complications associated with endoscopic procedures, a minority of them are still related to the limitations of the instruments that are used in achieving the goal of minimally invasive treatment $[1,2]$. This is especially true for novel indications, such as EUSguided gastroenterostomy [3], natural orifice transluminal endoscopic surgery (NOTES) [4], or submucosal endoscopy [5]. Similarly, endoscopic necrosectomy is cumbersome, being performed with tools borrowed from the armamentarium of other procedures, which may therefore have designs that are not suitable for the performance of all of the different steps in endoscopic necrosectomy. The presented case suggests the need for dedicated accessories in order to improve procedural efficiency and avoid complications.

Endoscopy_UCTN_Code_CPL_1AL_2AD

\section{Competing interests}

Alberto Larghi is a consultant for Boston Scientific Corp. The other authors have no relevant competing interests.
The authors

Mihai Rimbaș ${ }^{1,2}$, Gianenrico Rizzati ${ }^{1,3}$, Antonio Gasbarrini ${ }^{3}$, Guido Costamagna ${ }^{1}$, Alberto Larghi'

1 Digestive Endoscopy Unit, Catholic University, Rome, Italy

2 Department of Gastroenterology, Colentina Clinical Hospital, Carol Davila University of Medicine, Bucharest, Romania

3 Department of Internal Medicine, Gastroenterology and Hepatology, Catholic University, Rome, Italy

\section{Corresponding author}

\section{Alberto Larghi, MD, PhD}

Digestive Endoscopy Unit, Catholic University, Largo A. Gemelli 8, 00168 , Rome, Italy

Fax: +39-06-30156581

alberto.larghi@yahoo.it

\section{References}

[1] Mergener K, Baillie J. Complications of endoscopy. Endoscopy 1998; 30: 230-243

[2] Suchanek S, Grega T, Zavoral M. The role of equipment in endoscopic complications. Best Pract Res Clin Gastroenterol 2016; 30: 667-678

[3] Itoi T, Ishii K, Ikeuchi $\mathrm{N}$ et al. Prospective evaluation of endoscopic ultrasonographyguided double-balloon-occluded gastrojejunostomy bypass (EPASS) for malignant gas- tric outlet obstruction. Gut 2016; 65: 193 195

[4] Donatsky AM. Assessing transgastric Natural Orifice Transluminal Endoscopic Surgery prior to clinical implementation. Dan Med J 2014; 61: B4903

[5] Gonzalez JM, Benezech A, Barthet M. Complications of submucosal endoscopy. Best Pract Res Clin Gastroenterol 2016; 30: 783 791

\section{Bibliography}

DOI https://doi.org/10.1055/s-0043-119974

Published online: 3.11.2017

Endoscopy 2018; 50: 79-80

(c) Georg Thieme Verlag KG

Stuttgart · New York

ISSN 0013-726X

\section{ENDOSCOPY E-VIDEOS}

https:/|eref.thieme.de/e-videos

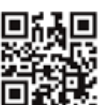

Endoscopy E-Videos is a free access online section, reporting on interesting cases and new

techniques in gastroenterological endoscopy. All papers include a high quality video and all contributions are freely accessible online.

This section has its own submission website at https://mc.manuscriptcentral.com/e-videos 